University of Nebraska - Lincoln

DigitalCommons@University of Nebraska - Lincoln

Faculty Publications, Department of Psychology

Psychology, Department of

2003

\title{
Socialization of Boys and Girls in Natural Contexts
}

Carolyn P. Edwards

University of Nebraska-Lincoln, cedwards1@unl.edu

Lisa Knoche

University of Nebraska-Lincoln, lknoche2@unl.edu

Asiye Kumru

Ozyegin University, asiye.kumru@ozyegin.edu.tr

Follow this and additional works at: https://digitalcommons.unl.edu/psychfacpub

Part of the Developmental Psychology Commons, and the Social and Cultural Anthropology Commons

Edwards, Carolyn P.; Knoche, Lisa; and Kumru, Asiye, "Socialization of Boys and Girls in Natural Contexts" (2003). Faculty Publications, Department of Psychology. 613.

https://digitalcommons.unl.edu/psychfacpub/613

This Article is brought to you for free and open access by the Psychology, Department of at DigitalCommons@University of Nebraska - Lincoln. It has been accepted for inclusion in Faculty Publications, Department of Psychology by an authorized administrator of DigitalCommons@University of Nebraska - Lincoln. 


\title{
Socialization of Boys and Girls in Natural Contexts
}

\author{
Carolyn Pope Edwards, Lisa Knoche, and Asiye Kumru
}

\section{Introduction}

Socialization is the general process by which the members of a cultural community or society pass on their language, rules, roles, and customary ways of thinking and behaving to the next generation. Sex role socialization is one important aspect of this general process. In common language, socialization means something like "learning to function in a social setting," as in "socialization of children in child care." This usage implies that the young children acquire social competence through the concerted efforts of adults, who carefully train and mold them to behave appropriately (thus we also speak of "puppy socialization"). In the social sciences, however, the meaning of "socialization" is more complex and does not carry the implication that children are simply the passive recipients or objects of the socialization process.

Rather, in recent years, concepts of socialization in general, and sex role socialization in particular, have been transformed along both theoretical and empirical dimensions. The theoretical aspect includes efforts to integrate social learning and cognitivist perspectives through a focus on self-socialization. Self-socialization can be defined as the process whereby children influence the direction and outcomes of their own development through selective attention, imitation, and participation in particular activities and modalities of interaction that function as key contexts of socialization. For example, many children prefer to observe and imitate same-gender models rather than the opposite gender, and to interact and participate in gender-typical activities. The empirical aspect of the reconceptualization of socialization thus involves a renewed focus on context. Whereas earlier studies of behavioral sex differences typically involved appraising individual behavioral dispositions across contexts, the new approach seeks ways to understand behavior within specific relational interactions and activity settings (e.g., the conversation of boys and girls in small or large groups) or in settings with children of mixed-age (e.g., in neighborhood games) versus the same age group (e.g., classmates at school).
Thus the goals of earlier work were to understand how, why, and at what age girls and boys begin to vary behaviorally along such dimensions as "nurturance," "aggression," and "dependency," including determination of how sex-typical dispositions are influenced by cultural factors. In contrast, the new approach seeks to answer such questions as the following. How are different kinds of gender-specific social behaviors called out or elicited by different contexts of socialization? How are gender differences influenced by children's relationship to their social companions-for example, their gender, age, status, and kinship relationship? How are gender differences influenced by different activity contexts (e.g., school, work, play) that we know are differentially distributed across cultural communities, depending on such factors as adult subsistence strategies, leisure patterns, family structures, household organizations, and forms of social networks? Finally, how are gender differences affected by where children are found, their location in space (e.g., distance from home)?

\section{Children's Companionship: Age, Gender, and Kinship}

Children's companions are those individuals whom they watch, imitate, and interact with in natural settings of home, school, neighborhood, and community. These social partners influence children's emerging gender expectations through face-to-face relationships in which children give and receive care, help, instruction, support, and cooperation, or where they engage in dominance struggles, conflicts, arguments, and fights. As they interact with different companions, children learn to discriminate the different categories of people in society, such as infants, elders, older versus younger siblings, extended family, household guests and visitors, and passers-by.

To understand the different socialization experiences of boys and girls, it is important to know what factors possibly influence children's companionship. Children around the world have different opportunities with re- 
spect to social companions. Their cultural community, developmental age, gender, and kinship composition strongly determine the company they keep. Cultural community shapes children's companionship through such macro features as the following: geographic layout, settlement pattern, cooperative networks, household composition, and age/gender division of labors (Whiting \& Edwards, 1988). For instance, in a community where the mother's primary responsibilities keep her in the vicinity of the house and adjacent garden areas, while the father's work takes him to a nearby town, the mother's companionship would necessarily be more salient to young children during the day than would the father's. In a community where families live in extended families with bilateral kinship, they will often have many houses where they can freely visit and play and a wide variety of cousins from both sides of their family with whom to interact.

Children's age has a strong influence on their choice of companions, much more so than does their gender in the early years. Age-related changes in children's physical, social, and intellectual capacities are necessarily related to changes in their social settings and their companions. For example, infants and toddlers require constant supervision and show dependency behaviors such as seeking comfort, protection, and food from the primary caregiver or designated guardians. They are more likely to be in the company of mothers or other female adults (grandmothers, aunts, or hired caregivers) rather than male adults in almost all cultural communities.

Preschool-age children expand their capabilities to do more things with more companions in a widening variety of settings (Garbarino \& Gilliam, 1980). They can now have younger as well as older companions in their playgroup, and they begin to learn about their position in the "pecking order" of childhood. As they become aware of their gender identity, they begin to show preferences for same-sex playmates and their cross-gender interaction decreases in settings when they can choose their companions, as at preschool or childcare.

During middle childhood, the experiences of children in different communities become even more divergent according to gender, as well as according to educational opportunities. In cultures where schooling is present for both girls and boys, children experience the very important transition of moving from a more home-centered to a more school-centered existence. School-age children interact frequently with same-age peers, the majority of whom are not kin, during half the day light hours. At this age, children seem to seek interaction with companions who are not their family members but who are like them in other ways. They may show avoidant or exclusive behavior toward children not of their gender, especially when they are playing in large groups (Whiting \& Edwards, 1988). Research shows that children's play in these single-gender groups involves high proportions of both egoistic conflict and sociability/ play behaviors, as if the children are using the group as a "laboratory" for learning how to negotiate and get along with peers in the culturally approved masculine or feminine way (Maccoby, 1998).

The age gap between the children and their companions is also important. When children interact with children who are older than they are by 3 or more years, they tend to display certain dependency behaviors (seeking proximity, exchanging information/inquiring, and watching/imitating) (Whiting \& Edwards, 1988). Toddlers and preschool-aged children seem especially motivated to imitate the behavior of older children, and learn much from contact with older siblings. When older children interact with younger and smaller children, they are much more likely to take on a dominant style of interaction than they are when they are with peers or older persons. Older children (especially boys) tend to decrease their contact with female family adults once they begin to attend school, but their contact with fathers may actually increase in communities where sons are allowed to help their fathers in work (Whiting \& Whiting, 1975).

Thus children's gender interacts with their age in influencing their preferred patterns of companionship. Throughout the world's cultures and subcultures, gender segregation for play and leisure are seen during the years of middle childhood. The same-gender peer play seems to appear around age 3 years (Hartup, 1983; Jacklin \& Maccoby, 1978), and to become predominant during the ages of 6-9 (Feiring \& Lewis, 1989; Whiting \& Edwards, 1988). These patterns may reflect in part the child's own preferences for friends and playmates (selfsocialization) as well as their parents' and other institutions' structuring of the social environment (Cochran \& Riley, 1987).

Children tend to compare their appearance, skills, and behavior with their same-gender peers who are close in age to them. Thus, interacting with same-gender companions may help them to establish gender identity and roles. However, girls usually have more access to adult females than boys do to adult males in their daily settings (Whiting \& Edwards, 1988). As a result, boys seem to seek out interaction with boys who are older 
than themselves, who may serve as models. Boys have more daily contact with male playmates in their dyadic settings than girls do with girl playmates (Feiring \& Lewis, 1989).

Finally, the organization of people in space and the social structure of households and neighborhoods affect the availability of kin versus non-kin companionship for children. For instance, in communities where children are restricted to the home environment, their main companions are usually their siblings and cousins, as observed among Abaluyia children of Kisa, Kenya (Weisner, 1984). Instead, where they have more autonomy to explore the neighborhood and more access to communal play areas or schools, they have more contact with nonrelatives and more chances to divide themselves into gender- and age-segregated playgroups, as is common in North America. In a study of United States social networks, Feiring and Lewis (1989) found that children aged 3, 6, and 9 years had a greater number and more daily contacts with nonkin than with kin. With increasing age, children significantly increased the number of kin with whom they were in contact, but they decreased nonsignificantly in their frequency of daily contact. Though boys and girls were not different in the proportion of kin versus nonkin with whom they were in contact, an increasing trend found that, with age, girls had more daily contact with kin than did boys.

\section{Children's Activities}

Activity settings allow children around the world to try out and experience different kinds of roles and occupations and to learn to navigate social relations with family and peers. As children move around different settings, they encounter different opportunities for work, play, learning, and sociability, and come in contact with different standing patterns of behavior and toys, objects, and natural materials to be manipulated. Boys and girls may or may not engage in the same sorts of activities, resulting in divergent socialization processes. A general review of the literature finds that parents behave surprisingly similarly in their explicit treatment of sons versus daughters, for example, in the rules they enforce (Maccoby and Jacklin, 1974). However, they do assign boys and girls to different settings (e.g., work vs. play) and encourage different patterns of companionship (e.g., time spent in mixed-age groups containing infants). Perhaps it is the cumulative effect of these large and small differences in task assignments, work, and play experiences that result in divergence of socialization experiences and outcomes for boys and girls (Morelli \& Tronick, 1991).

Children's activities in rural subsistence communities are often focused on responsible work (e.g., cleaning, gardening, herding, childcare), whereas in contemporary industrial communities, children are often put into organized play settings (e.g., preschools, schools, and afterschool programs). Around the world, girls and boys engage in different proportions of work versus play (Whiting \& Edwards, 1988), and these differences contribute to the gender-socialization process.

Activities can be thought of as "directed" or "undirected" (Munroe et al., 1983; Munroe, Munroe, \& Shimmin, 1984). Directed activities are ones that are specifically assigned to children by an authority figure, perhaps a parent or older sibling. They include such things as caring for younger siblings, household work, and errands outside the home. The age at which children are directed toward particular activities depends upon their society. In communities where women take a leading role in subsistence work, children (but especially girls) are recruited by their mothers to take on more responsible tasks at a younger age (Edwards \& Whiting, in press). In communities where boys can be easily incorporated into the work of the adult men (hunting, fishing, farming), and where that work is time consuming and labor intensive, boys move relatively early into work roles. Undirected activities are less structured, leaving the child to set the course for the event, as for example in free play or idle sociability. Both directed and undirected activities can be identified across cultural contexts, and both contribute to gender role development.

In a study of Australian youth aged 6-7 years, boys were found to be more engaged in competitive sports, and girls in ballet and dance (Russell \& Russell, 1992). In many studies (e.g., Edwards, 2000), girls have been more often observed playing with dolls, handling household objects, and participating in dress-up and art activities. Their play activities and toy preferences more often focus on domestic roles and nurturance. In contrast, boys are often found playing with store-bought or handmade vehicles, weapons, building materials, sports equipment, or other objects considered culturally masculine. In Senegal, the pretend play of girls focuses on domestic activities over the course of childhood; boys engage in domestic pretend play at age 2 , but increasingly tum to themes involving transportation and hunting as they get older (Bloch \& Adler, 1994). 
Types of play vary considerably by context. A reanalysis of the Six Culture data found that in locations where work predominated over play, all children were relatively unlikely to engage in fantasy play, perhaps because they were enacting such scenarios in real life. For example, instead of playing with dolls, young children could care for infant siblings, tend their household fire, and handle sharp cooking tools (Edwards, 2000). Furthermore, in communities where children had freedom to venture beyond the bounds of the immediate home and yard, they engaged in considerable amounts of creative-constructive play (e.g., building dams, making whistles and mud pies out of natural materials, and creating slingshots). The most "playful" children were found in Taira, Okinawa, where their workloads were light and they were supervised by all of the village adults collectively, giving them considerable freedom to move around the village (Edwards, 2000).

In some cultures, gender roles are impressed upon young children through directed, often work-related, activities. Through work, children can learn adult roles and skills (Nsamenang, 1992). In the Children of Different Worlds project, boys as young as age 4 years were trained to care for livestock (Whiting \& Edwards, 1988). In fact, animal care was generally a male task, especially with large animals such as cattle or water buffalo. In Rogoff's (1981) study of Guatemalan children, children were beginning to perform gender-specific work tasks by age 5 or 6 , with boys gathering firewood and feeding animals, and girls running errands and doing cleaning. This same division of labor was noted for an American middle-class sample (Bloch \& Walsh, 1985), where girls at age 5-6 years were directed to perform more housework, and again in a Caribbean sample of youth (Lange \& Rodman, 1992). Likewise, in a study of Senegalese children, girls were assigned more responsible work than boys starting at age 5 and 6 years (Bloch \& Adler, 1994). Certainly, however, children's work is not always gender specific. Mothers with heavy workloads recruit both sons and daughters to help (e.g., with gardening), and in households where there is no child of the appropriate gender to perform a gender-specific activity, children may be expected to cross over and do opposite-gender chores; for example, boys will clean or care for infants, and girls will tend to animals or repair fishing equipment (Ember, 1973; Lange \& Rodman, 1992).

Task assignment is thus a strong influence of the socialization process. Ember (1981) describes task assignment as an unconscious effort on the part of caretakers to transmit gender-specific information. For example, mothers in Senegal were found to be more likely to ask girls than boys to do work, and more likely to pull girls away from their play activities to perform responsible work (Bloch \& Adler, 1994). Across societies, girls are generally engaged in more responsible work than boys (Whiting \& Edwards, 1973). In a West African community, girls aged 8-10 years were often found caring for younger siblings, family members, and neighbor children (Nsamenang, 1992). In most cultures, females continue to be seen as responsible for children, and as young females become adults they expect to take on responsibility for children (Best \& Williams, 1997).

In sum, cultures around the world socialize boys and girls, through both direct and indirect means, to understand their gender role in society. The work activities of children reflect gender differences, with girls engaged in more household tasks and responsibilities than boys. Leisure and play activities between the sexes also vary, with girls focusing more on domestic scenarios and nurturance, and boys engaging in competitive and large-motor activities. Socialization through these activities, while discrete, generally results in separate societal rules and roles for the sexes. The activities in which children engage-both work and leisure-provide important learning opportunities for children, to help them become knowledgeable, informed participants in their culture.

\section{The Settings of Socialization}

Just as the activities in which children engage contribute to gender socialization, where children work and play also has important implications. The settings in which children spend their time shape those behaviors they can observe, tryout, rehearse, and master. The impact on socialization is directly related to the strength of the setting. Some contexts of development are considered "strong" and other situations "weak" (Snyder \& Ickes, 1985). In strong contexts, the range of behaviors that an individual is permitted to display is limited. The situation almost dictates the individual's response. Weak contexts allow more variability; the situation does not demand a specific behavioral or emotional response. With regard to gender socialization, many social situations are relatively strong, particularly for older children who are more aware of gender stereotypes and expectations. These strong contexts demand gender-appropriate behaviors, whereas 
weak-context environments allow children more flexibility in behaving outside or beyond the bounds of gender constraints.

Girls and boys tend to occupy different locations in space, along with some shared venues (Maccoby, 1998). In general, boys tend to play outdoors and in relatively large groups. When possible, they combine undirected play with their work, for example, interspersing roughhousing and chasing games with tending animals in the fields. Girls are more likely to be found playing with two to three peers in an indoor setting, or assisting inside with household chores, or outside performing errands such as going to the market or getting water or fuel. Girls also spice up their work with fun, especially through conversation, games, or singing. They engage in conversations more readily than boys do, while boys engage in more physical activity (Best \& Williams, 1997).

The school setting can be seen as both a "strong" and "weak" context for gender behaviors, depending on the specific location. For example, the cafeteria is a strong context, where boys and girls separate to different tables if given the choice. Likewise, on the playground, boy and girl groups take over separate spaces. Girls usually play around the periphery of the playground, while boys occupy a larger more central space. In fact, boys take up 10 times more space on the playground and often invade girls' activities (Maccoby, 1998; Thorne, 1994). The Children of Different Worlds project found that in societies where all the boys and girls go to school together, same-gender interaction was very high during free play, thereby resulting in more gender segregation than was generally found in the homes and neighborhoods (Whiting \& Edwards, 1988). Within the classroom, however, creative and constructive activities, such as art, manipulative, and dramatic play, can promote gender integration. For instance, in a social studies project, boys and girls can work cooperatively on tasks and are more likely to overlook gender differences than outside in the playground. The teacher's presence can attract both girls and boys to circle around nearby, causing them to mingle and interact.

Neighborhoods are generally "weaker" contexts than school settings with respect to gender roles. Owing to the limited number of playmates available, they often promote play that is mixed as to gender and age, and many favorite group games (such as "hide-andseek;' kick ball, and tag) attract children of all ages, boys and girls equally. Cross-gender play is also common when children collect in small groups or pairs, and when children have known one another for a long period of time and have built up trust and friendship. The more children are present in a space, and the more unfamiliar they are with one another, the more likely they will segregate based on gender.

The Children of Different Worlds spot observations revealed boys to be generally farther from home than were girls, in contexts that are considered weak in regard to gender socialization but strong in terms of peer pressure. Girls' movement away from the home was restricted in some societies, and they left the home area most often when following a predictable path doing a "directed" chore such as gathering water, collecting firewood, or going to the shop (Whiting \& Edwards, 1988). Boys had more freedom to wander beyond the home environment in undirected play where they were less accountable to figures of authority and perhaps more free to experiment in their behavior and follow their curiosity. On the other hand, we know from other research that when boys play together in groups, they strongly pressure one another toward what they consider masculine behavior (by ridiculing boys who do not measure up) (Carter \& McCloskey, 1984; Fagot, 1984). Thus, boys tum their free play away from home into strong contexts for gender role socialization.

The Children of Different Worlds project found that during directed activities, boys were found farther from home than girls in four of the six communities, and these differences were maintained during undirected play. In fact, it was during undirected activities that gender differences were maximized. Boys spent more time in locations and activities (such as rough-and-tumble play) that accentuated gender differences. Girls were generally nearer the home environment, more often engaged in directed activities with specific task or supervision responsibilities, interspersed with undirected intervals of leisure and socializing.

\section{Children's Behavior: Nurturance, Dependency, Prosaically Acts, and Aggression}

In this final section, we discuss four categories of child behavior (nurturance, dependency, pro social acts, and aggression) that appear at an early age and are important outcomes of the kinds of socialization processes we have described. Children's behavior seems to have certain similar characteristics across cultures because of 
their universal developmentally-based needs and desires. However, there are also important differences tied to cultural experiences. All four categories of behavior are particularly reciprocal in the child's dyadic interaction with their companions, and they are subjected to a cultural channeling that specifies under what circumstances and to whom the child can display them.

Nurturance can be defined as offering help and support to an individual who is in a state of need. Although there are variations in the styles and situations in which it is expected to express nurturance, it is a recognizable universal across culture. With age, children are more capable of perceiving, understanding, and meeting others' needs and wants, and then responding to them. For example, they learn how to offer food to distract a crying toddler or how to encourage a friend with a smile.

In almost all societies, infants and toddlers receive higher proportions of nurturance than do older children because of their relative helplessness and vulnerability as well as their cute and endearing physical characteristics (Braten, 1996; Edwards, 1986, 1993; Whiting \& Edwards, 1988). Infant crying seems to elicit nurturance behavior from even very young children (Zahn-Waxler, Friedman, \& Cummings, 1983). When infants grow older and become more mobile, independent, and demanding, they still need to be watched, protected, and instructed. However, toddlers are in many ways harder to care for than infants. They are still small and defenseless, but they seem to elicit many pro socially dominant behaviors from others (for instance, commands to desist from dangerous and annoying behaviors, and suggestions about how to eat their food properly) rather than the pure nurturance behavior that they formerly received (Whiting, 1983; Whiting \& Edwards, 1988).

Both older boys and girls tend to be highly nurturing toward babies. However, girls are more nurturing than boys to toddlers, other children, and adults (Whiting \& Edwards, 1988). In most societies, girls are assigned as caretakers of babies and have more opportunity to practice nurturance than do boys. Girls are more frequently in the company of their mothers and more eager to imitate the maternal role. In their play, girls are more likely to act out scenes from familiar settings, such as the home and school where they can rehearse and create domestic roles involving nurturing interpersonal relationships and nurturance (Edwards, Knoche, \& Kumru, 2001). Thus, girls seem to have more opportunities in everyday life to practice nurturance than do boys.
Dependency behavior can be described as seeking help, attention, permission, information, emotional support, or material resources. Because of the helplessness of the human infant, dependency behavior is strong at the beginning of life and is elicited and rewarded by caretaking adults at least some of the time. One would expect that the dependency would then decrease as the child becomes more mature and competent. However, research has documented no clear-cut changes in age in overall levels of dependency behavior during childhood. Maccoby and Masters (1970) discussed these findings with reference to the different types of dependent behaviors. They noted that clinging and proximity-seeking behavior decrease with age, while help- and attention-seeking behavior remain high. Similarly, Whiting and Edwards (1988) suggest that a child's dependency tendencies toward mother does not so much decrease as change in style from early to middle childhood. Children's preferred style tends to shift from more physical and intimate modes toward ones like help, attention, information, and permission-seeking that rely on verbal skills and help them act in accord with cultural values. Thus, children's dependency changes in format with age, becoming less intimate and proximal, but it does not disappear.

Findings on gender differences in child's dependency are decidedly mixed. Luo boys from Kenya were observed to exhibit significantly more dependency behavior than were the girls (Ember, 1973). However, many studies from Western and non-Western societies have shown little or no sex differences in overall dependency behavior (Maccoby \& Jacklin, 1974; Whiting \& Edwards, 1973). Ember (1981) suggested that girls and boys might exhibit different types of dependency behavior. For instance, in the Six Cultures data, girls tended to seek help and physical contact more than boys in the 3-6-year-old age range, but boys seemed to seek attention and material goods more than girls once they were about 7 years old (Edwards \& Whiting, 1974).

Prosocial behavior can be described as voluntary acts intending to meet the needs of others. Pro social behavior tends to increase with age because of developmental changes in children's cognitive, socio-emotional, and physical competence (Eisenberg \& Fabes, 1998). In most societies, children are expected to carry more responsibility at home as they become mature and to display more pro social acts. Studies with Western and non-Western samples show that older children displayed higher proportions of prosocial behaviors compared with their younger peers (Eisenberg, 1992; 
Eisenberg \& Fabes, 1998; Whiting \& Edwards, 1973, 1988; de Guzman, Edwards, \& Carlo, 2002).

Socialization pressures and learning might play an important role in children's prosocial tendencies. From toddlerhood on, children experience socialization pressure to learn the rudiments of pro social behavior (Whiting \& Edwards, 1988). In cultures where children have more opportunities to interact with infants, they seem to acquire capacities for prosocial behavior naturally and smoothly. Likewise, where they grow up in the company of elders who need their assistance, they learn prosocial values about respect and care of the very old.

Literature about gender differences in pro social behavior has produced mixed conclusions. For example, studies conducted in contemporary Western societies suggest that girls seem to perform more pro social behavior than boys, at least during late childhood and adolescence (Eisenberg \& Fabes, 1998). Barry, Bacon, and Child (1957) found that socialization pressure toward nurturance, obedience, and responsibilities was much higher for girls than for boys across 110 societies. However, some studies have produced contrary results. For example, de Guzman et al. (2002) found no gender differences in prosocial behaviors for the Gikuyu children of Ngecha, Kenya; for these children, social contexts of work and childcare proved to be strong socialization settings that elicited high levels of prosocial behavior from both boys and girls.

Finally, aggression can be defined as satisfying the actor's own needs through an ascendant or commanding style that inflicts some kind of injury or loss of resources to the other. Although psychologists continue to debate about whether aggression is innate or learned, research has documented that positive reinforcement and permissive conditions increase the level of aggressive behaviors. Indeed, Western research shows that parents who reward and encourage aggression seem to have aggressive children (Bandura \& Walters, 1963). The same is true of mothers in non-Western societies, who have high levels of controlling and reprimanding behavior and who uphold children's dominant/aggressive and insulting behaviors to meet their egoistic needs (Whiting \& Edwards, 1988). Indeed, societies where people value and reward aggression produce highly aggressive individuals (Chagnon, 1968; Ember \& Ember, 1994). Punitive socialization promotes rather than decreases children's hostility and aggression (Zigler \& Child, 1969). This can occur in cultural communities with extended family households where outward aggression cannot be tolerated with so many people living together (Harrington \& Whiting, 1972).
Whiting and Edwards (1988) found that physical teasing, assaulting, and insulting occurred at similar levels whether older children are interacting with younger ones, or vice versa. However, there was also very consistent evidence of gender differences in aggression, and this has been confirmed across both Western and nonWestern societies. Past about age 3, boys generally show more aggression than girls (Maccoby \& Jacklin, 1974; Whiting \& Edwards, 1973).

Children seem to come into the world with similar but not identical endowments for dyadic interaction across cultures. Cultural scripts in many societies then set girls and boys on different courses by exaggerating, reducing, or redirecting any emerging gender differences through the mechanisms of constraining the company that children keep, the activities they perform, and the locations in which they spend their time. Children too are active in their own gender socialization and, whenever they can, make predictable choices about whom they will observe and imitate, how, where, and with whom they will play, and when and how they will contribute to the care of others and the useful work needed to carry on daily life in their community.

\section{References}

Bandura, A., \& Walters, R. H. (1963). Aggression. In H. W. Stevenson (Ed.), Child psychology. The sixty-second yearbook of the National Society for Education (pp. 364-415). Chicago: University of Chicago Press.

Barry, H., Bacon, M. K., \& Child, 1. L. (1957). A cross-cultural survey of some sex differences in socialization. Journal of Abnormal Psychology, 55, 327-332.

Best, D., \& Williams, J. (1997). Sex, gender and culture. In J. W. Berry, M. H. Seagall, \& C. Kagitcibasi (Eds.), Handbook of crosscultural psychology (Vol. 3) (pp. 163-212). Boston, MA: Allyn \& Bacon.

Bloch, M. N., \& Adler, S. M. (1994). African children's play and the emergence of the sexual division of labor. In J. L. Roopnarine, J. E. Johnson, \& F. H. Hooper (Eds.), Children's play in diverse cultures (pp. 148-178). Albany, NY: State University of New York Press.

Bloch, M. N., \& Walsh, D. (1985). Young children's activities at home: Age and sex differences in activity, location, and social context. Children's Environment Quarterly, 2(2), 34-40.

Braten, S. (1996). When toddlers provide care: Infants' companion space. Childhood, 3, 449-465.

Carter, D. B., \& McCloskey, L. A. (1984). Peers and the maintenance of sex-typed behavior: The development of children's conceptions of cross-gender behavior in their peers. Social Cognition, 2, 294-314.

Chagnon, N. A. (1968). Yanomamo. New York: Holt, Rinehart, and Winston.

Cochran, M. M., \& Riley, D. (1987). Mother's reports of children's social relations: Agents, concomitants and consequences. In J. 
Antrobus, S. Salzinger, \& M. Hamner (Eds.), Social networks of children, adolescents and college students. Hillsdale, NJ: Erlbaum.

de Guzman, M. R. T., Edwards, C. P., \& Carlo, G. (2002, July). Prosocial behaviors in context: A study of the Gikuyu children of Ngecha, Kenya. Poster session presented at the biennial meeting of the International Society for the Study of Behavioral Development, Ontario, Ottawa, Canada.

Edwards, C. P. (1986). Another style of competence: The caregiving child. In A. Fogel \& G. F. Melson (Eds.), Origins of nurturance: Developmental, biological, and cultural perspectives on caregiving. Hillsdale, NJ: Erlbaum.

Edwards, C. P. (1993). Behavioral sex differences in children of diverse cultures: The case of nurturance to infants. In M. E. Pereira \& L. A. Fairbanks (Eds.), Juvenile primates: Life history, development, and behavior. New York: Oxford University Press.

Edwards, C. P. (2000). Children's play in cross-cultural perspective: A new look at the Six Cultures study. Cross-Cultural Research, 34, 318-338.

Edwards, C. P., Knoche, L., \& Kumru, A. (2001). Play patterns and gender. Encyclopedia of Women and Gender, 2, 809-815.

Edwards, C. P., \& Whiting, B. B. (1974). Women and dependency. Politics and Society, 4, 343-355.

Edwards, C. P., \& Whiting, B. B. (Eds.), (in press). Ngecha: A Kenyan community in a time of rapid social change. Lincoln, NE: University of Nebraska Press.

Eisenberg, N. (1992). The caring child. In A. Kamiloff-Smith, \& M. Cole (Eds.), The developing child. Cambridge, MA: Harvard University Press.

Eisenberg, N., \& Fabes, R. A. (1998). Prosocial development. In W. Damon (Series Ed.) \& N. Eisenberg (Vol. Ed.), Handbook of child psychology; Vol. 4. Social and personality development (5th ed., pp. 701-778). New York: Wiley.

Ember, C. (1973). Feminine task assignment and social behavior of boys. Ethos, 1, 424-439.

Ember, C. (1981). A cross-cultural perspective on sex differences. In R. H. Munroe, R. L. Munroe, \& B. B. Whiting (Eds.), Handbook of cross-cultural development. New York: Garland STPM Press.

Ember, C. R., \& Ember, M. (1994). War, socialization, and interpersonal violence: A cross-cultural study. Journal of Conflict Resolution, 38, 620-646.

Fagot, B. 1. (1984). The child's expectations of differences in adult male and female interactions. Sex Roles, 11 (7/8),593-600.

Feiring, C., \& Lewis, M. (1989). The social network of girls and boys from early through middle childhood. In D. Belle (Ed.), Children's social networks and social supports. New York: Wiley.

Garbarino, J., \& Gilliam, G. (1980). Understanding abusive families, Lexington, MA: Lexington Books.

Harrington, C., \& Whiting, J. W. M. (1972). Socialization process and personality. In F. L. K. Hsu (Ed.), Psychological anthropology (New ed., pp. 469-508). Cambridge, MA: Schenkman.

Hartup, W. (1983). Peer relations. In P. H. Mussen (Series Ed.) \& E. M. Hetherington (Vol. Ed.), Handbook of child psychology: Vol. 4. Socialization, personality and social development. New York: Wiley.

Jacklin, C. N., \& Maccoby, E. (1978). Social behavior at 33 months in same-sex and mixed-sex dyads. Child Development, 49, 557-569.
Lange, G., \& Rodman, H. (1992). Family relationships and patterns of childrearing in the Caribbean. In I. E. Sigel (Series Ed.) \& J. L. Roopnarine \& D. B. Carter (Vol. Ed.), Annual advances in applied developmental psychology: Vol. 5. Parent-child socialization in diverse cultures (pp. 185-198). Norwood, NJ: Ablex.

Maccoby, E. E. (1998). The two sexes: Growing up apart: Coming together. Cambridge, MA: Harvard University Press.

Maccoby, E. E., \& Jacklin, C. N. (1974). The psychology of sex differences. Stanford, CA: Stanford University Press.

Maccoby, E. E., \& Masters, J. C. (1970). Attachment and dependency. In P. H. Mussen (Vol. Ed.), Carmichael's manual of child psychology (Vol. 2, pp. 73-157). New York: Wiley.

Morelli, G. A., \& Tronick, E. Z. (1991). Parenting and child development in the Efe foragers and Lese farmers of Zaire. In M. H. Bornstein (Ed.), Cultural approaches to parenting (pp. 91-114). Hillsdale, NJ: Erlbaum.

Munroe, R. H., Munroe, R. L., Michelson, C., Keol, A., Bolton, R., \& Bolton, C. (1983). Time allocation in four societies. Ethnology, 22, 355-370.

Munroe, R. H., Munroe, R. L., \& Shimmin, H. S. (1984). Children's work in four cultures: determinants and consequences. American Anthropologist, 86, 369-379.

Nsamenang, A. (1992). Human development in cultural context: a third world perspective (pp. 149-157). Newbury Park, CA: Sage. Rogoff (1981). Adults and peers as agents of socialization. Ethics, 9, 18-36.

Russell, A., \& Russell, G. (1992). The socialization of Australian boys and girls in middle childhood for independence and achievement. In I. E. Sigel (Series Ed.) \& J. L. Roopnarine \& D. B. Carter (Vol. Ed.), Annual advances in applied developmental psychology: Vol. 5. Parent-child socialization in diverse cultures (pp. 53-74). Norwood, NJ: Ablex.

Snyder, M., \& Ickes, W. (1985). Personality and social behavior. In G. Lindzey \& E. Aronson (Eds.), Handbook of social psychology: Vol. 2. Research methods (3rd ed., pp. 883-947). New York: Random House.

Thorne, B. (1994). Gender play: Girls and boys in school. New Brunswick, NJ: Rutgers University Press.

Weisner, T. (1984). The social ecology of childhood: A cross cultural view. In M. Lewis (Ed.), Beyond the dyad. New York: Plenum.

Whiting, B. B. (1983). The genesis of prosocial behavior. In D. L. Bridgeman (Ed.), The nature of prosocial development (pp. 221-242)

Whiting, B. B., \& Edwards, C. P. (1973). A cross-cultural analysis of sex differences in the behavior of children aged 3-11. Journal of Social Psychology, 91,171-188.

Whiting, B. B., \& Edwards, C. P. (1988). Children of different worlds: The formation of social behavior. Cambridge, MA: Harvard University Press.

Whiting, B., \& Whiting, J. (1975). Children of six cultures: A psychocultural analysis. Cambridge, MA: Harvard University Press.

Zahn-Waxler, C., Friedman, S. L., \& Cummings, E. M. (1983). Children's emotions and behaviors in response to infants' cries. Child Development, 54, 1522-1528.

Zigler, E., \& Child, I. L. (1969). Socialization. In G. Lindzey \& E. Aronson (Ed.), The handbook of social psychology (2nd ed., Vol. 3, pp. 450-589). Reading, MA: Addison-Wesley 